\title{
Characterisation and optimisation of diclofenac sodium orodispersible thin film formulation
}

Ibrahim Khadra*1, Mohammad A. Obeid ${ }^{2}$, Claire Dunn ${ }^{1}$, Stewart Watts ${ }^{1}$, Gavin Halbert ${ }^{3}$, Steve Ford ${ }^{1}$ and Alexander Mullen ${ }^{1}$

${ }^{1}$ Department of Pharmaceutical Sciences, Institute of Pharmacy and

Biomedical Sciences, University Of Strathclyde, Glasgow, UK.

2 Faculty of Pharmacy, Yarmouk University, Irbid, Jordan.

${ }^{3}$ Cancer Research-UK, Institute of Pharmacy and Biomedical Sciences, University Of Strathclyde, Glasgow, UK.

*Corresponding author: Ibrahim.khadra@strath.ac.uk

\section{Abstract}

Oral Thin Film (OTF) is a newly emerging drug delivery system which has many benefits for patients. Although there has been some formulation of OTF products, these have mainly been as confectionary or dental health products. The most significant benefit of this dosage format will only be realised once more pharmaceutical products become available. Within this paper, OTF strips containing Diclofenac Sodium were prepared using the solvent casting method and then characterised to ensure the method could conform to acceptable levels of uniformity, the mean (SD) diclofenac sodium content was 25.43(1.39) mg, range 22.84-27.44 mg. Bioburden was tested against coliforms, yeasts and moulds and all results were confirmed to be $<10 \mathrm{CFU} / \mathrm{g}$, 
also similar dissolution profile when compared to a commercial product to ensure biowaiver. An acceptable level of uniformity of mass was produced. K$\mathrm{F}$ titration was employed to reduce the water content of the strips and it was found to be acceptable, this represented a level of water which would not be viable for microbial growth. The technique employed here in the production of OTF resulted in high quality products and amenability to being up scaled. Furthermore, the characterisation method was also sufficient to assess the quality of the products and may be used for future analysis of OTF pharmaceuticals.

\section{Key Words}

Oral Thin Film, drug delivery, Diclofenac Sodium, solvent casting method. 


\section{Graphical abstract}
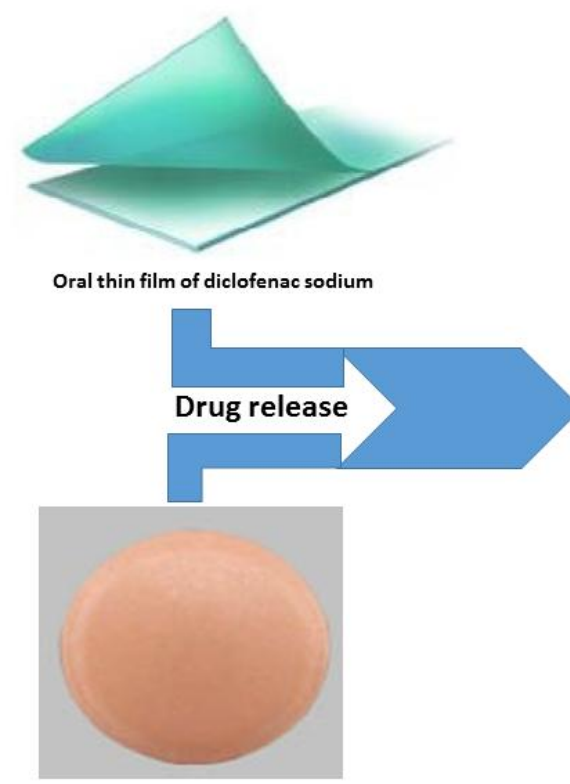

Oral tablet of diclofenac sodium

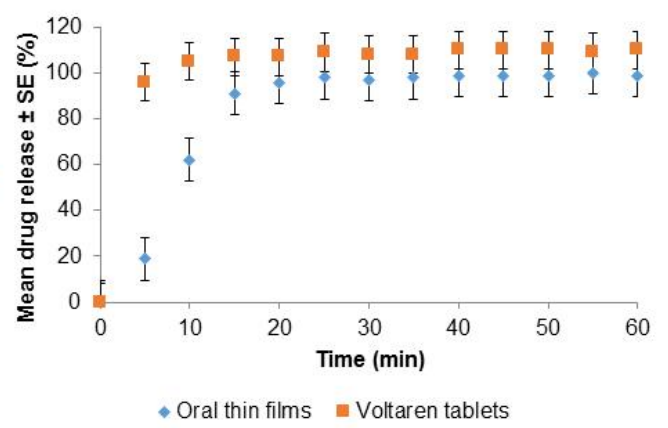

$\downarrow$ Oral thin films $\backsim$ Voltaren tablets 


\section{Introduction}

Diclofenac is one of the most commonly prescribed non-steroidal antiinflammatory drugs (NSAIDs), used in the treatment of pain and inflammatory conditions since its introduction in 1970s. Like all NSAIDs, diclofenac exerts its effects through the inhibition of prostaglandin synthesis by blocking cyclooxygenase enzymes COX-1 and COX-2. It is available in two salt forms: diclofenac sodium and diclofenac potassium, with the sodium salt being the most commonly prescribed [1]. Indications for its use include rheumatic disease, gout, migraine, musculoskeletal and post-operative pain. It is also used topically in actinic keratosis, ophthalmically for peri- and post-operative inflammation and seasonal allergic conjunctivitis, and has been associated with an opioid-sparing effects in cancer pain therapy [2-4]. Diclofenac is very well absorbed via the oral route, undergoes extensive first-pass metabolism, binds almost entirely to plasma proteins at therapeutic levels and has a halflife of approximately $1-2$ hours [5].

Orodispersible thin films (OTFs) were first established as breath fresheners and have since progressed to the delivery of active pharmaceutical ingredients (APIs). Composed principally of one or more water soluble, filmforming polymers, OTFs dissolve very rapidly in contact with saliva, releasing the active ingredient(s) without the need to chew or drink water [6]. This makes them ideally suited to elderly or paediatric populations, who may have difficulty swallowing other solid oral dosage forms such as tablets or capsules. OTFs are thin films typically the size of a postage stamp and can be formulated using minimal food or pharmaceutical grade excipients. They are 
discreet, convenient and easy to take. Typically, alongside the film-forming polymer(s), an OTF formulation will include a plasticizer e.g. glycerol, to give the film strength and flexibility [7]. Flavour and sweetener combinations can also be included to help mask bitter tasting drugs [8, 9]. Commonly used filmforming polymers include cellulose-based polymers such hydroxypropyl methylcellulose, pullulan, starches and maltodextrins [10]. In 2010, Zuplenz ${ }^{\circledR}$ became the first FDA approved prescription only medicine in an OTF formulation for the delivery of ondansetron in the treatment of postoperative chemotherapy- and radiotherapy-induced nausea and vomiting [11]. More recently in February 2012, Applied Pharma Research were successful in marketing a prescription only zolmitriptan based OTF product for the treatment of migraine [12].

Many APIs have an unpleasant, bitter taste. This can result in non-compliance with drug regimens where the formulation is unacceptable to the patient; this is especially true in the case of paediatrics. Taste masking of pharmaceutical actives may be achieved through a variety of methods and technologies, from addition of simple flavour and sweetener combinations through to more complex systems such as drug complexation with ion exchange resins or cyclodextrins [13-15].

To overcome the above mentioned problems and to increase the compliance of diclofenac sodium preperaions, the primary aim of this project was to formulate a rapidly dissolving, immediate release thin film which contained 25 mg of diclofenac sodium for oral delivery. The film should be flexible and non- 
brittle with suitable mechanical properties to resist handling. The film should also have acceptable organoleptic properties - taste, aroma, mouth feel with effective taste masking of the bitter active pharmaceutical ingredient.

\section{Materials and methods}

\subsection{Oral thin film preparation}

Diclofenac sodium (Amoli Organics Pvt. Ltd., India), glycerol (Sigma Aldrich, UK), spearmint mild flavour (Givaudan, Switzerland), citric acid (Sigma Aldrich, UK), polyethylene glycol 1500 (Fluka, Germany), sucralose (Tate \& Lyle, UK) and water were weighed and mixed using an Ultra-Turrax ${ }^{\circledR}$ T50 basic S2 homogeniser (IKA-Werke GMBH \& Co., Germany; Serial No. D79219). Hydroxypropyl methylcellulose E3 (Colorcon, UK) was added gradually to the mixture under continuous mixing until a homogenous, viscous solution formed, Table 1 listed quantities required. The solution was then degased under vacuum. The viscous solution was cast onto polymer coated paper using an Automatic Film Applicator (Sheen Instruments Ltd., Kingston, UK; Serial No. 5254290) with a Micrometer Adjustable Film Applicator 1117/250 mm (Sheen Instruments Ltd., Kingston, UK; Serial No. 094606/50) that been adjusted to give the right thickness of the film and dried at $40^{\circ} \mathrm{C}$. Oral thin films were cut into the correct strip weight (110 mg) using a rotary blade. 
Table 1. Ingredients used for the preparation of Diclofenac Sodium Oral thin film

\begin{tabular}{|l|l|}
\hline Material & Target Weight (g) \\
\hline Diclofenac Sodium & 12.80 \\
\hline Glycerol & 1.00 \\
\hline Citric Acid & 3.50 \\
\hline PEG 1500 & 2.80 \\
\hline Sucralose & 2.80 \\
\hline Spearmint Mild flavour & 2.80 \\
\hline Distilled Water & 100.00 \\
\hline HPMC E3 & 26.00 \\
\hline
\end{tabular}

\subsection{HPLC method}

An isocratic high performance liquid chromatography method (HPLC) was optimized with a view to develop an assay method for diclofenac sodium. A Dionex HPLC system with Dionex autosampler ASI-100 was used for batch analyses which was coupled to a UV detector. A Spheroclone ODS $150 \times 4.6$ $\mathrm{mm} \times 5 \mu \mathrm{m}$ C18 column was employed. A mobile phase consisting of methanol (Rathburns, Blackburn, UK) and water (80:20) adjusted to $\mathrm{pH} 4.0$ using glacial acetic acid with a flow rate of $1 \mathrm{~mL} / \mathrm{min}$ at $280 \mathrm{~nm}$ wavelength was found to produce an acceptable retention time, plates and good resolution for diclofenac sodium. Calibration standards in the $0.1-0.5 \mathrm{mg} / \mathrm{mL}$ range were prepared from a $0.5 \mathrm{mg} / \mathrm{mL}$ diclofenac sodium stock solution, prepared in mobile phase. The stock solution was stored at $4^{\circ} \mathrm{C}$ protected from light.

Linearity was assessed across a concentration range representing $40-200 \%$ of the anticipated test sample concentration. Between day variability was 
established to determine intermediate precision. Five concentrations were measured on two consecutive days; three repeat measurements were performed at each concentration.

\subsection{Content, mass uniformity and cleaning verifiction}

The uniformity of content was assessed by high performance liquid chromatography (HPLC). Calibration standards of diclofenac sodium $0.5,0.4$, $0.3,0.2$ and $0.1 \mathrm{mg} / \mathrm{mL}$ in mobile phase were prepared and run on the HPLC. The peak area was calculated for each standard solution and results plotted against concentration to yield a calibration curve for determination of sample batches. 20 randomly selected strips were individually weighed and dissolved in mobile phase, and assayed using HPLC.

\subsection{Dissolution}

Dissolution testing was carried out according to compendial paddle methodology [16]. Phosphate buffer ( $\mathrm{pH} 6.8,900 \mathrm{~mL})$ was used as the dissolution media to represent intestinal $\mathrm{pH}$. The USP paddle apparatus (COPLEY DIS 6000, Serial: 15302) was used with a paddle speed of $50 \mathrm{rpm}$ at $37^{\circ} \mathrm{C} \pm 0.5^{\circ} \mathrm{C}$ using the specified dissolution media and solutions were analysed using spectrophotometry at $280 \mathrm{~nm}$ (PG Instrument, T70+ UV/VIS Spectrometer). Measurements were taken every 5 minutes until completion and the average percentage drug release $(n=6)$ was plotted against time. Voltaren ${ }^{\circledR} 50$ mg orodispersible tablets (Novartis, Germany) were used as a commercially available comparator product and dissolution was carried out by the same method. 


\subsection{Microbial bioburden}

Oral thin film samples were sent to ALcontrol Laboratories (Bellshill, UK) for microorganism testing. Samples were tested for aerobic colony count, coliforms, yeasts and moulds as per ISO 11737-1 which is used to determine a population of microorganism within products.

\subsection{Karl Fischer titration (water content)}

Karl Fisher titration analysis was performed using a DL37 coulometric titrator (Mettler Toledo, Leicester, UK) with Coulomat CG and A reagents (Sigma Aldrich, Poole, UK). The titrimeter accuracy was checked using Hydranal 1.00 and 10.0 water standards (Sigma Aldrich). The solvents used were HPLC grade methanol (Rathburns, Blackburn, UK) and anhydrous DMSO (Sigma Aldrich, UK). Karl Fisher analysis of the oral strips were performed by adding a single strip to approximately $5 \mathrm{ml}$ of solvent (methanol or DMSO). DMSO solubilized/suspended the strips over a few minutes, whereas with methanol the strips remained intact. Samples being analysed in methanol were left overnight before analysis. Water content determination was performed in triplicate and corrected for solvent water content.

\subsection{Organoleptic evaluation}

Taste acceptability was measured by a taste panel (single blinded) consisting of human volunteers $(n=6)$ using diclofenac sodium $25 \mathrm{mg}$ oral thin films compared with a blank film (flavour only). The volunteers were asked to allow the oral thin films to disperse in their mouths and to record the palatability of 
individual formulations after $\mathrm{X}$ seconds before removing the residue of the dosage form from their mouths without ingesting. The volunteers then rinsed any formulation residue from their mouths by gargling with distilled water before evaluating another sample. The bitterness level was recorded on taste evaluation sheets. A four point scale was used to indicate acceptability: 1 star $=$ very bitter, 2 stars $=$ moderate to bitter, 3 stars $=$ slightly bitter, and 4 stars $=$ tasteless/taste masked.

\section{Results}

\subsection{HPLC method validation}

A good linear relationship was found when the peak area of diclofenac sodium was plotted against the diclofenac sodium standard concentrations $\left(R^{2}=\right.$ 0.9916). Results of between day variability are presented in Table 2.

Table 2. Intermediate precision. Between day variability in peak area.

\begin{tabular}{|l|l|l|l|l|}
\hline \multirow{2}{*}{$\begin{array}{l}\text { Diclofenac sodium } \\
\text { concentration } \\
(\mathrm{mg} / \mathrm{mL})\end{array}$} & \multicolumn{3}{|l|}{ Day 1 } & \multicolumn{2}{l|}{ Day 2 } \\
\cline { 2 - 5 } & $\begin{array}{l}\text { Mean AUC } \\
\left(\mathrm{mAU}{ }^{*} \mathrm{~min}\right)\end{array}$ & $\begin{array}{l}\text { RSD } \\
(\%)\end{array}$ & $\begin{array}{l}\text { Mean AUC } \\
\left(\mathrm{mAU}^{*} \mathrm{~min}\right)\end{array}$ & $\begin{array}{l}\text { RSD } \\
(\%)\end{array}$ \\
\hline 0.5 & 158.49 & 0.55 & 151.08 & 0.57 \\
\hline 0.4 & 130.75 & 0.02 & 125.87 & 1.18 \\
\hline 0.3 & 98.85 & 0.19 & 93.81 & 1.12 \\
\hline 0.2 & 65.73 & 1.10 & 64.91 & 2.63 \\
\hline 0.1 & 33.30 & 3.03 & 30.93 & 1.33 \\
\hline R-sq & 0.999 & & 0.9978 & \\
\hline
\end{tabular}

\subsection{Uniformity of content and mass}

The mean (SD) weight of the oral thin films dosage units $(n=20)$ was 110.95(5.86) mg, range 100-121 mg. The mean (SD) diclofenac sodium content was 25.43(1.39) $\mathrm{mg}$, range $22.84-27.44 \mathrm{mg}$. Although no specifications exist with respect to oral thin films, all dosage units conformed to pharmacopoeial requirements for immediate release tablet preparations 
since no dosage unit deviated from the stated content $(25 \mathrm{mg})$ by more than $10 \%$. In addition, no individual dosage unit exceeded the mean strip weight by more than $10 \%$, therefore the batch also conformed to standards of mass uniformity.

\subsection{Cleaning verification}

Swabs of the work surface and balance used for weighing the ingredients were subject to the HPLC analysis as per section 2.3 after cleaning with soap and water, all the results were below the lower limit of quantification.

\subsection{In vitro dissolution profiling}

The results of the in vitro dissolution testing in phosphate buffer $(\mathrm{pH} \mathrm{6.8,} 900$ $\mathrm{mL}$ ), to represent intestinal $\mathrm{pH}$, over time were shown in figure 1 . This represent the average percentage drug release $(n=6)$ against time. The results were compared with the release profile of the commercially available comparator product (Voltaren ${ }^{\circledR} 50 \mathrm{mg}$ orodispersible tablets) using the same dissolution conditions. 


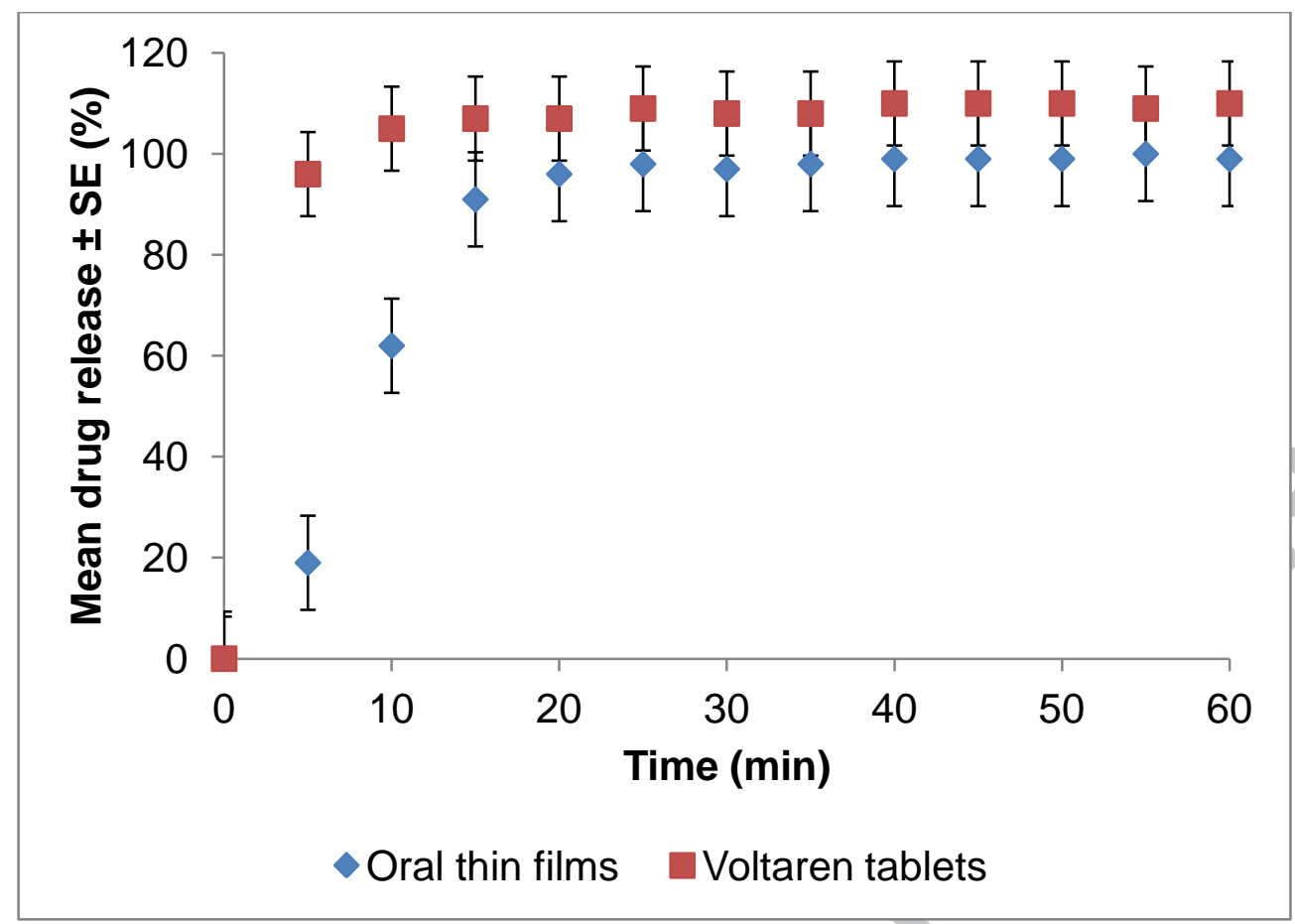

Figure 1. Drug release profiles of oral thin films vs. commercial comparator at pH 6.8.

\subsection{Karl Fischer titration (water content)}

The mean (SD) percentage water content for the oral thin films in methanol and hygroscopic DMSO were 11.9(0.4) and 15.2(0.9) percent respectively. The result obtained from the DMSO was higher than that of methanol. With methanol the strip did not dissolve (intact) and therefore only the free water was measured, whilst using DMSO the strips were completely dissolved, and therefore both the free and bound water could be measured.

\subsection{Microbial bioburden}

Samples were tested for aerobic colony count, coliforms, yeasts and moulds and all results were confirmed to be $<10 \mathrm{CFU} / \mathrm{g}$. The batch therefore conformed to the pharmacopoeial acceptance criteria for microbiological quality of non-sterile dosage forms i.e. total aerobic microbial count $<10^{3}$ $\mathrm{CFU} / \mathrm{g}$ and total yeast and mould count $<10^{2} \mathrm{CFU} / \mathrm{g}$ [17]. 


\subsection{Organoleptic testing}

Results of the in vivo taste evaluation found the diclofenac sodium orodispersible thin films dissolved completely in the mouth in an average of 60 seconds compared to the blank film, which dissolved in around 15 seconds. The volunteers rated the drug containing films 3 stars on average compared to 4 stars with the placebo film. This indicated that only a slight bitterness remained and a reasonable masking of the active ingredient was achieved.

\section{Discussion}

Drug delivery by an oral thin film (OTF) is a new formulation that is currently under development for use in general clinical practice. An oral thin film is made from hydrophilic polymers that rapidly dissolve in the oral cavity. OTFs have been examined since the 1970's when the anaesthetic lidocaine was used for dental applications using a polymer film [18]. More recently in 2001, Pfizer's Warner-Lambert consumer healthcare division launched a breath freshener using OTF technology - Listerine ${ }^{\circledR}$ PocketPaks ${ }^{\text {TM }}$ [19]. The films produced a "minty" flavour in the mouth by rapidly dissolving the on the tongue. Utilisation of OTF technology will provide a fast and effective mechanism for drug delivery. Absorption from the oral mucosa will be rapid and will avoid degradation by the acidic $\mathrm{pH}$ and digestive enzymes of the gastro-intestinal tract. The drug will also bypass first pass metabolism by the liver allowing for the administration of lower doses that still produce high efficacy therefore reducing the risk of side effects [20]. Moreover, ease of 
administration suggests that OTFs are more likely to be tolerated by patients providing that they be of an acceptable taste.

Therfore, in this study, a rapidly dissolving oral thin films containing $25 \mathrm{mg}$ diclofenac sodium was successfully formulated and a taste mask of diclofenac sodium was achieved using a simple mixed sweetener and flavour strategy. The film possessed good mechanical properties, sufficient to resist handling, being flexible and non-brittle. Rapid drug release was achieved with complete release (>80\%) within 15 minutes. Furthermore, a rapid and sensitive reverse phase HPLC method with UV detection was successfully used for the determination of diclofenac sodium in an oral thin film. The batch of oral thin films conformed to Pharmacopoeial standards of uniformity in terms of drug content and mass. Acceptable results were also achieved with respect to tensile strength, water content and micro-organism testing. The results of the Karl-Fischer titration and microbial bioburden testing supported the expectation that the preservative-free formulation would possess minimal available water to support significant microbial growth this comply with the Biofilm limited UK aaceptable standard criteria of less than $20 \%$ of water content. Orodispersible thin films are ideal for patients with swallowing difficulties as they dissolve very rapidly on the tongue in saliva, without the need to chew or drink water. This gives them advantage over other solid dosage designs such as tablets or capsules. Oral thin films are particularly suited to paediatric populations who may find swallowing other solid oral dosage forms difficult. Our diclofenac orodispersible film dissolved within 60 seconds on contact with saliva which is comparable to commercial orodispersible tablet products [21, 22]. Although a sparse Pharmacopoeial 
monograph for orodispersible thin films exists under oromucosal products, no specifics are given as to how quickly the formulation should disintegrate [23]. However, the British Pharmacopoeial states that for orodispersible tablet disintegration, units must disintegrate within 3 minutes, and our formulation complies with this requirement.

\section{Conclusion}

Here, we have succusfuly formulated an oral thin films fo diclofenac sodium which dissolved rapidly with excellent taste masking of diclofenac sodium. The film was strong enough to withstand any mechanical handling. This formulated OTF was able to achieve rapid release of diclofenac sodium within 15 minuts after administration. This OTFs are ideal for patients with swallowing difficulties such as elderly and pediatric patients.

\section{Acknowledgments}

The authors gratefully acknowledge the financial support of Biofilm Limited UK and the assistance and input of the multiple colleagues associated with this project from Cancer Research UK (CRUK). 


\section{References}

1. Moore RA, Derry S, Mcquay HJ, Wiffen PJ. Single dose oral analgesics for acute postoperative pain in adults. The Cochrane database of systematic reviews doi:10.1002/14651858.CD008659.pub2

10.1002/14651858.CD008659.pub2.(9), Cd008659 (2011).

2. Dodds A, Chia A, Shumack S. Actinic keratosis: rationale and management. Dermatology and therapy 4(1), 11-31 (2014).

3. Palmero M, Bellot JL, Alcoriza N, Garcia-Cabanes C, Orts A. The ocular pharmacokinetics of topical diclofenac is affected by ocular inflammation. Ophthalmic research 31(4), 309-316 (1999).

4. Bjorkman R, Ullman A, Hedner J. Morphine-sparing effect of diclofenac in cancer pain. European journal of clinical pharmacology 44(1), 1-5 (1993).

5. Davies NM, Anderson KE. Clinical pharmacokinetics of diclofenac. Therapeutic insights and pitfalls. Clinical pharmacokinetics 33(3), 184213 (1997).

6. Kathpalia H, Gupte A. An introduction to fast dissolving oral thin film drug delivery systems: a review. Current drug delivery 10(6), 667-684 (2013). 
7. Dixit R, Puthli S. Oral strip technology: overview and future potential. Journal of controlled release 139(2), 94-107 (2009).

8. Arya A, Chandra A, Sharma V, Pathak K. Fast dissolving oral films: an innovative drug delivery system and dosage form. Int J ChemTech Res 2 576-583 (2010).

9. Dixit RP, Puthli SP. Oral strip technology: overview and future potential. J Control Release 139(2), 94-107 (2009).

10. Garsuch V, Breitkreutz J. Comparative investigations on different polymers for the preparation of fast-dissolving oral films. J Pharm Pharmacol 62(4), 539-545 (2010).

11. U.S. Food and Drug Administration. ZUPLENZ (ondansetron) oral soluble film, $4 \mathrm{mg}$ and $8 \mathrm{mg}$. Drug Approval Package (26th April 2013), (2011).

12. Apr Applied Pharma Research. APR Applied Pharma Research ("APR") and Labtec GmbH ("Labtec") announce the European approval of Zolmitriptan Oral Dispersible Film (ODF). (06/11/2014), (2012).

13. Walsh J, Cram A, Woertz K et al. Playing hide and seek with poorly tasting paediatric medicines: do not forget the excipients. Advanced drug delivery reviews 73 14-33 (2014).

14. Szejtli J, Szente L. Elimination of bitter, disgusting tastes of drugs and foods by cyclodextrins. European journal of pharmaceutics and biopharmaceutics : official journal of Arbeitsgemeinschaft fur Pharmazeutische Verfahrenstechnik e.V 61(3), 115-125 (2005).

15. Pein M, Preis M, Eckert C, Kiene FE. Taste-masking assessment of solid oral dosage forms--a critical review. International journal of pharmaceutics 465(1-2), 239-254 (2014).

16. British Pharmacopoeia Commission. British Pharmacopoeia 2014 Online. Appendix XII B. ANNEX: Recommendations on Dissolution Testing. (06/10/2014), (2014).

17. British Pharmacopoeia Commission. British Pharmacopoeia 2015 Online. British Pharmacopoeia Volume V. Appendix XVI D. Microbiological Quality of Non-sterile Pharmaceutical Preparations and Substances for Pharmaceutical Use. (04/06/2015), (2015). 
18. Karki S, Kim H, Na S-J, Shin D, Jo K, Lee J. Thin films as an emerging platform for drug delivery. asian journal of pharmaceutical sciences 11(5), 559-574 (2016).

19. Gali AK. Fast dissolving dosage forms. Int J Pharm Sci Inv 2(11), 14-17 (2013).

20. Dahiya M, Saha S, Shahiwala AF. A review on mouth dissolving films. Current drug delivery 6(5), 469-476 (2009).

21. Liew KB, Tan YT, Peh KK. Characterization of oral disintegrating film containing donepezil for Alzheimer disease. AAPS PharmSciTech 13(1), 134-142 (2012).

22. Yan YD, Woo JS, Kang JH, Yong CS, Choi HG. Preparation and evaluation of taste-masked donepezil hydrochloride orally disintegrating tablets. Biological \& pharmaceutical bulletin 33(8), 13641370 (2010).

23. British Pharmacopoeia Commission. British Pharmacopoeia 2015 Online. British Pharmacopoeia Volume III. Formulated Preparations: General Monographs. Oromucosal preparations. (15/07/2015), (2015). 